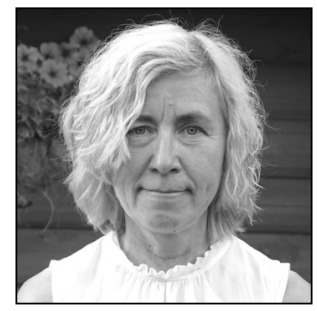

Marika Žmenja

Doctoral student University of Tartu

\title{
Provision of Health-care Service over the Internet - the Legality of E-consultations in Estonia
}

\section{Introduction}

Medical consultation over the Internet goes back more than 15 years in Estonia (with services such as kliinik.ee, inimene.ee, and arst.ee). In more recent years, several new Web sites for that purpose have been set up (e.g., amor.ee and peaasi.ee), along with ones that offer new services in this domain, among them medical and genetic testing for various pathological conditions - which may include laboratory services coupled with sales of medical devices (as with sportsgene.ee, testikodus.ee, and fertify.eu) and treatment (e.g., koneravi.ee).

A new type of service was added to the Estonian Health Insurance Fund (EHIF) list of health-care services $^{{ }^{*}}{ }^{1}$ in $2013-e$-konsultatsioon, consultation between a specialist and general practitioner ${ }^{{ }^{*}}$ that takes place via the health-information system for meeting with regard to a specific patient.

In 2015, the portal netiarst.ee ${ }^{*}$ was launched. It soon found itself the subject of a Health Board investigation. On the basis of the explanation it received from the portal operator, the Health Board maintained the position that the service offered via the portal was a health-care service and therefore required an activity licence. ${ }^{*} 4$

As online medical consultation encompasses diverse services - general information and advice, patient instruction, general and personalised counselling (whether for a fee or free of charge), and others - the following question arises: at what point may online medical consultation become provision of a health-care service - i.e., an e-consultation, which would be governed by the same legal rules as conventional healthcare services? Is e-consultation possible in the existing legal framework, or must the legal norms be adapted accordingly?

1 Vabariigi Valitsuse 29.12.2016 määrus nr 157 „Eesti Haigekassa tervishoiuteenuste loetelu“ ['Government of the Republic regulation no. 157 of 29 December 2016, 'List of Estonian Health Insurance Fund health-care services']. - RT I, 30.12.2016, Subsection 7 (25). The EHIF currently funds e-consultation in 16 specialities.

2 The general practitioner is the first person to consult with in the event of illness. The general practitioner refers the patient to a medical specialist; gives advice pertaining to the prevention of diseases; takes preventive measures; and issues health certificates, certificates of incapacity for work, and prescriptions.

3 At the moment, netiarst.ee is temporarily out of service.

4 In response, netiarst.ee's operator chose not to apply for an activity licence and instead redesigned its service such that it intermediates a specialist service supplied by health-care service providers. The Health Board letter on the subject is in the possession of the author. 
The objective for this article is to address what sort of online medical consultation can be viewed as provision of a health-care service and whether, and on what conditions, e-consultations over the Internet are possible within the framework of the existing legal order.

\section{E-consultation as telemedicine}

There is no generally accepted definition of telemedicine. A communication from the European Commission has taken the approach that telemedicine is provision of health-care services that uses information and communication technology (ICT) devices in situations wherein the health-care specialist and patient (or, alternatively, two health-care specialists) are in different physical locations. This involves secure transmission of medical data and information in the form of text, sound, images, or other formats for the purpose of the prevention, diagnosis, treatment, and aftercare needed by the patient. Telemedicine encompasses, among other things, teleconsultation, along with online consultation / electronic appointments or videoconferencing between health-care specialists. ${ }^{*}$ We can conclude from this definition that telemedicine is not an independent medical field as sometimes mistakenly believed; rather, telemedicine refers to the way in which health-care service is provided, and it should be contrasted against face-to-face communication, which still can utilise ICT devices.

E-consultation is differentiated from consultation provided by conventional means by the fact that the patient and health-care service provider are physically separate and communicate while at a physical distance from each other. The communication can take place in real time - by videoconferencing, a Skype or other 'voice over IP' connection, or telephone - or with a time lag, via e-mail or instant messaging. Such a method can be used also in fields of medicine that require an actual physical examination of the patient: The examination can be conducted by a second health-care provider, who sends the findings from the examination to the consulting health-care service provider. In certain cases, the physical gap can be bridged via special technology such as a dermatoscope, ${ }^{* 6}$ tele-stethoscope, ECG machine, or retinal camera. Special booths have been introduced in telemedicine projects in France where people can talk to a doctor over a video bridge and have their vital signs measured. ${ }^{*}$ As technology advances and as equipment is developed and introduced that allows physical examinations to be conducted from a physical distance, e-consultations will prove feasible in more and more cases.

The rules currently in force in Estonia do not necessarily require examination of the patient in order for a consultation to be considered provision of a health-care service. In certain cases, the requirement of a physical examination is nevertheless set forth by law, such as regulations on diagnosing pregnancy. ${ }^{*} 8$

Thus, e-consultation - i.e., provision of health-care service to a patient without having direct physical contact with that patient - is not directly prohibited in the Estonian legal space, unlike, for instance, in Germany and Poland, where providing health-care services without a physical examination of the patient is forbidden. ${ }^{*} 9$

5 Communication from the Commission to the European Parliament, the Council, the European Economic and Social Committee and the Committee of the Regions on telemedicine for the benefit of patients, healthcare systems and society (COM(2008)689 final). Available at http://eur-lex.europa.eu/legal-content/EN/TXT/PDF/?uri=CELEX:52008DC068 9\&from=EN (most recently accessed on 17.4.2017).

6 A dermatoscope is a special camera for taking an enlarged picture of a birthmark or other skin formation and sending it electronically via the Dermtest software (dermtest.ee) to a dermatologist or oncologist for diagnosis procedures.

7 La première cabine de télémédecine ouvre en Bourgogne (The first telemedicine booth opens in Burgundy). - Business Herald, 31.3.2014. Available at http://business-herald.com/non-classe/la-premiere-cabine-de-telemedecine-ouvre-en-bourgogne (most recently accessed on 1.5.2017).

8 Raseduse katkestamise ja steriliseerimise seadus (Termination of Pregnancy and Sterilisation Act). - RT I 1998, 107, 1766; RT I, 20.2.2015, 11, Section 10. English text available at https://www.riigiteataja.ee/en/eli/ee/Riigikogu/ act/505032015003/consolide (most recently accessed on 17.4.2017).

9 UNIversal solutions in TElemedicine Deployment for European HEALTH care. Available at http://united4health.eu/ wp-content/uploads/2015/10/D5.5-v1.0-U4H-Industry-Report-on-Telemedicine-Lega-land-Regulatory-Framework.pdf (most recently accessed on 15.4.2017). The opinion in Germany is that treatment and diagnosis over the Internet is insufficient, as it runs the risks of misdiagnosis and thereby poses a risk to patients (Entwurf eines Vierten Gesetzes zur Änderung arzneimittelrechtlicher und anderer Vorschriften (Draft of a Fourth Act on the Amendment of provisions on medicinal products and other regulations.)), available at https://www.bundesgesundheitsministerium.de/fileadmin/Dateien/3_Downloads/ Gesetze_und_Verordnungen/GuV/A/AMG-Novelle_GE.pdf (most recently accessed on 28.6.2017). 


\section{E-consultation as a health-care service}

\subsection{The definition of health-care services}

According to Subsection 2 (1) of the Health Services Organisation Act (HSOA), health services are the activities of health-care professionals carried out for the prevention, diagnosis, or treatment of diseases, injuries, or intoxication in order to reduce the malaise of persons, prevent the deterioration of their state of health or development of diseases, and restore their health. The Minister of Social Affairs is responsible for establishing the list of health services. ${ }^{* 10}$

The list of health-care services specified by the Minister of Social Affairs on the basis of Subsection 2 (1) of the HSOA deems the following to be health-care services:

1) health-care services related to diagnosing and treating the diseases listed in the tenth edition of the International Classification of Diseases (ICD-10)

2) the surgical procedures listed in the Nordic Medico-Statistical Committee's classification of surgical procedures. ${ }^{* 11}$

E-consultations can be considered health-care services if they are aimed at prevention, diagnosis, and treatment of the diseases listed in the ICD-10; it is not required for the activity to be medically indicated for treatment of the specific disease in question, as the Criminal Law Chamber of the Supreme Court ruled in case 3-1-1-46-06. ${ }^{* 12}$

In its letter to the operator of netiarst.ee, the Health Board likewise maintained that in the case of a service wherein a health-care professional provides a specific person, in accordance with that person's need for assistance (determined by the health-care professional on the basis of a conversation, images, additional information sent, or other content), with advice, recommendations, and instructions for prevention of disease, injury, or intoxication and asks, probes, and/or processes data in some other manner to diagnose the person's condition and/or gives the person output thereof that consists of treatment recommendations and instructions designed to alleviate that specific person's complaints, to keep said person's health from worsening or the disease from becoming exacerbated, and to restore health, this constitutes a health-care service. ${ }^{*} 13$

Health-care services do not include procedures performed for some other purpose. In the case of genetic testing offered by SportsGene OÜ on its Web site, K. Pormeister, in the article 'Tarbijale suunatud geenitestid Eesti oigusruumis' (Consumer-oriented Genetic Tests in the Estonian Legal Space), takes the position that genetic testing does not fit the HSOA's definition of health-care services in either its nature or its purpose; the objective is neither the prevention nor the diagnosis of disease. Hence, genetic testing directed at consumers represents a service that cannot be treated as a health-care service and that is not part of a research study. ${ }^{* 14}$ Still, it is hard to concur completely. The Fertify gene test for ascertaining female fertility, intermediated by SportsGene OÜ and supplied by FutuTest OÜ, could be viewed as a health-care service. ${ }^{*} 15$

The e-health strategy working group on law and ethics is of the opinion that if a service offered online may be a health-care service in form and substance while the goal of the health-care professional is not to provide a health-care service, it is possible to side-step definition of that service as a health-care service if the consumer is informed by way of the terms of service that the online service does not constitute provision of a health-care service. ${ }^{* 16}$

10 Tervishoiuteenuste korraldamise seadus (Health Services Organisation Act). - RT I 2001, 50, 284; RT I, 21.2.2017, 5. English text available at https://www.riigiteataja.ee/en/eli/513032017001/consolide (most recently accessed on 17.4.2017).

11 Ministry of Social Affairs regulation no. 13 of 10 January 2002, establishing a list of health-care services. RTL 2002, 14, 180 (in Estonian), Section 1.

12 RT III 2006, 28, 255 (in Estonian).

13 See Note 4 above.

14 K. Pormeister. Tarbijale suunatud geenitestid Eesti õigusruumis (Consumer-oriented Genetic Tests in the Estonian Legal Space). Juridica IV (2016), pp. 263-270 (in Estonian).

15 Fertify is a genetic test for evaluating women's potential for conception and their age-related infertility risk. On the basis of the test, individual-specific recommendations are made for preserving natural fertility and for additional medical studies related to fertility.

16 This is in line with the view of law and ethics expressed in the Government of the Republic's e-health strategy up to 2020. See the report of the working group on law and ethics, available at https://www.sm.ee/et/strateegia (most recently accessed on 19.3.2017) (in Estonian). 
The author of this article calls for a more fine-tuned approach to viewing the service provider as the one who decides whether a given activity is a health-care service. Provision of a health-care service involves providing a regulated economic service; such activity may be launched only if certain conditions are met (there is an activity-licence requirement). If a person's activity substantively matches the definition for provision of a health-care service, an activity licence must be sought, ${ }^{, 17}$ irrespective of how the service provider or the parties to the service refer to it. Initiating economic activity without having applied for an activity licence can result in an administrative body imposing state supervision measures that render further conducting of economic activity impossible if there is a heightened or significant threat to public order. ${ }^{* 18}$

The Health Board expressed the position that what is relevant is not how health-care professionals themselves view and refer to the service but, rather, how service-users view the service and for what purpose they contact its providers - netiarst.ee in the specific case considered. If a given person must initiate contact with the service and has been provided with details for various specialists beforehand and been given an explanation of what the service is being provided as an alternative to, there is reason to believe that it is, in fact, a health-care service. ${ }^{*} 19$

Consultation with a health-care professional over the Internet can, therefore, be viewed as a health-care service. If a health-care professional wishes to dispense health-related advice online in such a manner as cannot be viewed as provision of a health-care service, that professional's activity cannot substantively meet the definition for a health-care service - said professional cannot diagnose a specific person on the basis of a request from that person, not even making a hypothetical diagnosis ${ }^{{ }^{20}}$, and cannot assign treatment or give treatment recommendations.

\subsection{Health-care service as a health-care professional's activity}

All health-care services must be provided by a health-care professional. Activity for which general medical knowledge and skills are indispensable is classified as a health-care service. ${ }^{* 21}$

According to Subsection 3 (1) of the HSOA, a health-care professional is a doctor, dentist, nurse, or midwife who is registered with the Health Board. For the purposes of the Medicinal Products Act, 'healthcare professionals' also covers pharmacists and assistant pharmacists providing pharmacy services at a general pharmacy or hospital pharmacy, provided that they have been registered in the national register of pharmacists and assistant pharmacists maintained by the Health Board in accordance with Subsection 55 (1) of the Medicinal Products Act (Subsection 3 (4) of the HSOA).

The EHIF's list of health-care services also includes services that, because they are performed by a person who is not a health-care professional, do not fulfil the definition specified in the HSOA. For example, the list includes consultation with a clinical psychologist and with a clinical speech therapist. ${ }^{* 2}$ Neither of these is a health-care professional. Yet under EHIF guidelines, their activities do constitute health-care services, as examinations and investigations are conducted and they provide consultation and put together a treatment plan. ${ }^{* 3}$ Going by the content descriptions in the EHIF's list of health-care services, psychotherapy may be carried out by a psychiatrist or clinical psychologist. ${ }^{* 24}$ This leads us to the question of whether consultation with a clinical psychologist supplied over the Internet can be considered a health-care service if its goal is to prevent, diagnose, and treat diseases.

17 Section 40 of the HSOA.

18 Majandustegevuse seaduse üldosa seadustik (General Part of the Economic Activities Code Act). - RT I, 25.3.2011, 1; RT I, 19.3.2015, 51, Subsection 67 (1). English text available at https://www.riigiteataja.ee/en/eli/527032015008/consolide (most recently accessed on 17.4.2017).

19 See Note 4 above.

20 Even in the course of provision of conventional health-care service, as a general rule, a hypothetical diagnosis is made at the first appointment with a doctor, which is then either corroborated with tests or not.

21 Svetlana Lokk-Kidava v. Estonia (see Note 12), paragraph 14.

22 List of EHIF health-care services, sections 36 and 37.

23 Speech therapy coding manual. Available at https://www.haigekassa.ee/sites/default/files/TTL/2016_08_12_logopeedia_ teenuste_juhend_kodulehele.pdf (most recently accessed on 19.3.2017) (in Estonian). See also the list of health-care service descriptions - psychiatry, available at https://www.haigekassa.ee/sites/default/files/TTL/2015_01_05_psyhhiaatria_ ttl2015_kirjeldused.pdf (most recently accessed on 19.3.2017) (in Estonian)

24 Ibid. 
In summary, it can be said that e-consultations carried out by health-care professionals can be considered provision of a health-care service if the provision of the service inevitably requires medical knowledge and the activity is aimed at the prevention, diagnosis, and treatment of a disease and restoring health.

In the interests of legal clarity and certainty, the definition of health-care service should be updated so that service providers know when their activities can be treated as provision of a health-care service and whether they need to apply for an activity licence if wishing to begin such activity. This would also create greater clarity for patients, and patient rights and protections would be better guaranteed. In the opinion of this author, the definition of health-care professional should be broadened such that clinical psychologists, speech therapists, and other specialists who provide, in essence, health-care services are considered healthcare professionals. The current situation is one in which, on the basis of Supreme Court interpretations, the activity of these professionals fundamentally fulfils the definition for health-care service and also appears on the EHIF's health-care service list yet formally is not considered a health-care service.

\subsection{Health-care service as an economic activity}

The Supreme Court has taken the position that only provision of a health-care service that is rendered in the framework of an economic or professional activity can be classified as a health-care service. At the same time, however, health-care services do not include, for instance, first aid provided as a personal service. ${ }^{{ }^{2} 5}$

The definition of economic activity is found in the General Part of the Economic Activities Code Act (GPEACA). ${ }^{* 26}$ Under Subsection 3 (1) of the GPEACA, economic activity is considered to be any permanent activity that is pursued independently to generate income and that is not prohibited pursuant to the law. If a notification or authorisation obligation has been established in respect of an activity, the activity is deemed to be an economic activity even if generating income is not its purpose (Subsection 3 (2)).

The explanatory memorandum to the GPEACA accounts for this by noting that the Estonian legal system encompasses persons who are not engaged in economic activity for the purposes of Subsection 4 (1) of the GPEACA yet whose activity a decision has been made should be subject to an activity-licence or registration requirement; this makes it necessary to set forth, as an additional criterion, that the concept of economic activity also extends to other activities in regard to which a notification or authorisation obligation has been established, even if the purpose of the activity is not to generate income (law in force pertains mainly to the social, health-care, and education sphere). If an additional criterion had not been established, the GPEACA would not apply to these persons and it would have been necessary to retain or set forth provisions that are redundant with those of the GPEACA.${ }^{*} 7$

Thus, provision of a health-care service is always considered an economic activity, as it is subject to an activity-licence requirement, even if the provision of health-care service is not permanent and/or takes place free of charge. ${ }^{*} 8$

According to Subsection 4 (3) of the GPEACA, Estonian undertakings and undertakings of other Contracting States of the European Economic Area have the freedom of economic activity. Under Subsection 5 (1) of the GPEACA, an undertaking is a natural or legal person who commences or pursues economic activities. According to Subsection 3 (2) of the Commercial Code, ${ }^{* 29}$ a sole proprietor shall submit a petition for his or her entry in the Commercial Register before commencement of the activity.

The HSOA governs the legal form in which medical procedures may be supplied as a service in the framework of economic and professional activity. For example, family physicians may practise as sole proprietors or through companies providing general medical care (Section 12); companies, sole proprietors, or foundations that hold corresponding activity licences may provide specialised outpatient care (Subsection 21 (1)); and a company or foundation that holds a corresponding activity licence may own a hospital (Subsection $22(2)$ ).

\footnotetext{
Svetlana Lokk-Kidava v. Estonia (see Note 12), paragraph 12.

Majandustegevuse seaduse üldosa seadustik (see Note 18, above).

27 See the text available at http://www.just.ee/sites/www.just.ee/files/elfinder/article_files/majandustegevuse_seadustiku_ uldosa_seaduse_eelnou_seletuskiri.pdf (most recently accessed on 19.3.2017) (in Estonian).

28 E.g., free-of-charge consultation supplied by health-care service providers online.

29 Äriseadustik (Commercial Code). - RT I 1995, 26, 355; RT I, 22.6.2016, 32. English text available at https://www.riigiteataja. ee/en/eli/513072016002/consolide (most recently accessed on 17.4.2017).
} 
Hence, according to the HSOA, a health-care professional meeting the definition in Subsection 3 (2) of the HSOA may provide e-consultations only if having registered as a sole proprietor or doing so through a company in a legal form allowed by the HSOA, after having been granted an activity licence for this purpose. Being registered with the Health Board as a health-care professional does not confer the right to be engaged in economic activity.

The report from the law and ethics working group expresses the conclusion that health-care services do not include intermediation of a health-care service, which is what the operator of netiarst.ee does in providing health-care service providers with a technical platform for service provision. According to the working group's conclusion, it should be treated as an information-society service. ${ }^{*} 30$ At the moment, the European Court of Justice (ECJ) has received questions from the Spanish government, which is seeking a preliminary decision on whether Uber ${ }^{*}{ }^{31}$ is a transport service or, instead, an information-society service provider. Some EU member states have taken the position that Uber is a transport company. ${ }^{* 32}$ On 11 May 2017, Advocate General Maciej Szpunar submitted an opinion in the case of Uber, according to which Uber's activity constitutes not an information-society service but a transport service. ${ }^{*} 33 \mathrm{~A}$ final decision on the case is expected before the end of the year. Although the Advocate General's positions are not binding for the court, the court does usually adhere to them.

The conclusions of the court may have an impact also on the interpretation of the services offered by netiarst.ee - whether they are a health-care service or an intermediary service. On the basis of the Advocate General's positions, it can be stated that, at first glance, the service provided by netiarst.ee could be a healthcare service, not an intermediary service. Whether an e-consultation is considered a health-care service or instead an intermediary service depends on the design of the service - is it a composite service, do healthcare professionals carry out independent economic activity, and so forth? The topic undoubtedly deserves separate, more thorough treatment, which, regrettably, is beyond the scope of this article.

\section{E-consultation as an activity subject to authorisation}

Under Subsection 16 (1) of the GPEACA, an undertaking must, in the cases specified by legislation, have an activity licence prior to commencement of economic activities in a given area of activity. According to the HSOA, health-care service may be provided only by sole proprietors or legal persons with an appropriate activity licence (subsections 7 (2), 18 (1), 21 (1), 22 (2), 25 (1), and $25^{1}(1)$ ).

Provision of a health-care service without an activity licence is an illegal economic activity. Subsection 372 (1) of the Penal Code stipulates that operating without an activity licence in an area of activity that requires one is a crime. ${ }^{*} 34$

The activity licence entitles an undertaking to commence economic activity and certifies that said undertaking has complied with certain requirements for economic activity in its area of activity. The activity licence also specifies secondary conditions for pursuing economic activity (Subsection 16 (2) of the GPEACA).

Under Subsection 40 (1) of the HSOA, an activity licence is required for provision of specialist medical care, provision of emergency medical care, supplying of general medical care on the basis of a practice list of a general practitioner, independent provision of nursing care, and independent provision of midwifery care.

The material requirements for economic activity that constitute the object of verification for the activity licence are, according to Subsection 42 (2) of the HSOA, that the staff, facilities, installations, and equipment necessary for the provision of specialised medical care comply with the requirements established on the basis of the HSOA.

30 See Note 16 above.

31 The netiarst.ee solution is similar to that used by Uber and the associated taxi-service app, offering a software solution that matches service providers (the driver is analogous to the health-care professional) to service consumers (in that case, people wanting to go from point A to point B rather than patients).

32 EU court asks: Is Uber an app or taxi service? CNET News. Available at https://www.cnet.com/news/is-uber-an-app-ortaxi-service-eu-court-asks/ (most recently accessed on 19.3.2016).

33 Opinion of Advocate General Szpunar delivered on 11 May 2017. Case C-434/15. Available at http://eu-rlex.europa.eu/ legal-content/EN/TXT/?uri=CELEX\%3A62015CC0434 (most recently accessed on 28.6.2017).

34 Karistusseadustik (Penal Code). - RT I 2001, 61, 364, RT I, 31.12.2016, 14. English text available at https://www.riigiteataja. ee/en/eli/519012017002/consolide (most recently accessed on 17.4.2017). 
These requirements are established in Minister of Social Affairs regulation 25 of 25 January 2002, 'Requirements for Facilities, Installations, and Equipment Necessary for Provision of specialised outpatient care'. ${ }^{3} 35$

The current legal provisions for application for activity licences do not enable sole proprietors or companies to apply for an activity licence for provision of health-care service over the Internet (e-consultations) if they do not have physical appointment rooms. Under Subsection 42 (2) of the HSOA, for an activity licence to be granted, the facilities must meet the requirements established on the basis of the HSOA. Accordingly, only health-care providers who already have an activity licence for provision of general or specialist medical care or independent provision of nursing care or who apply jointly for one have the right to apply for an activity licence to provide health-care service online. This brings us to the question of whether it is justified to restrict the right of provision of e-consultation to only those health-care providers having a physical reception unit with rooms.

Although the above-mentioned Ministry of Social Affairs regulation permits consultations with patients even if the provider does not possess the equipment needed for examination, legal acts treat face-to-face appointments but not health-care service provided online as an outpatient health-care service. Similarly to the law on online sales of medicinal products, which requires a general pharmacy activity licence, legal requirements applicable to a health-care service provider specify that said provider must have an activity licence for provision of a health-care service; this gives it the right to provide e-consultation as well. ${ }^{*} 36$

\section{E-consultation as an information-society service}

E-consultation is simultaneously both a health-care service and an information-society service and is subject to the Information Society Services Act (ISSA). ${ }^{*} 37$ An information-society service is a service that is provided in the form of economic or professional activities at the direct request of a recipient of the services, without the parties being simultaneously present at the same location, and such services involve the processing, storage, or transmission of information by electronic means intended for the digital processing and storage of data (ISSA, Subsection 2 (1)).

Information-society services must be entirely transmitted, conveyed, and received by electronic means of communication. Services provided by means of fax or telephone call and television or radio services and broadcasting in the sense applied in the Broadcasting Act are not information-society services (Subsection 2 (1) of the ISSA). This means that a patient's visit to a doctor during which the doctor uses, for example, electronic devices is not an information-society service, as there is no physical distance. ${ }^{*} 38$ If the contact between patient and doctor takes place with a physical distance between them and is made possible by electronic applications, as in telemedicine, then it may be an information-society service. ${ }^{*} 39$

According to Recital 18 of the preamble to the E-Commerce Directive, ${ }^{*} 40$ activities that by their very nature cannot be carried out at a distance and by electronic means, such as medical advice requiring the physical examination of a patient, are not information-society services. The directive also applies to doctors' Web sites that promote their activity; physicians' recommendations that do not require physical examination of the patient, that are provided for a fee, or whose costs are covered by advertising or sponsorship; and the online sale of medicinal products. ${ }^{*} 41$

35 RTL 2002, 25, 353; RT I, 1.6.2016, 8.

36 Ravimiseadus (Medicinal Products Act). - RT I 2005, 2, 4; RT I, 4.5.2016, 4, Subsection 31 (5 ${ }^{1}$ ). English text available at https://www.riigiteataja.ee/en/eli/516052016002/consolide (most recently accessed on 17.4.2017).

37 Infoühiskonna teenuse seadus (Information Society Services Act). - RT I 2004, 29, 191; RT I, 6.1.2011, 12. English text available at https://www.riigiteataja.ee/en/eli/513012015001/consolide (most recently accessed on 1.5.2017).

38 Directive 98/48/EC of the European Parliament and of the Council of 20 July 1998 amending Directive 98/34/EC laying down a procedure for the provision of information in the field of technical standards and regulations. Official Journal $\mathrm{L} 217$, 05/08/1998, pp. 0018-0026. Annex V, Art. 1.

39 S. Callens et al. E-health and the Law. London: Kluwer Law International and International Law Association 2003 , p. 103.

40 Directive 2000/31/EC of the European Parliament and of the Council of 8 June 2000 on certain legal aspects of information society services, in particular electronic commerce, in the Internal Market ('Directive on electronic commerce'). Official Journal L 178, 17/07/2000, pp. 0001-0016.

41 European Commission. Study on legal and regulatory aspects of eHealth: 'Legally eHealth'. Deliverable 3, Issues of Liability and Consumer Protection. Available at http://www.crid.be/pdf/public/5603.pdf (most recently accessed on 15.4.2017). 
For effectively guaranteeing the freedom to provide service and legal certainty for providers and recipients of services, the law of the Member State applying to the service provider's location is applied with regard to information-society services. Hence, an information-society service provided via a place of business located in Estonia must meet the requirements arising from Estonian law, whichever EU or EEC member state the service is provided in. ${ }^{*}{ }^{4}$

According to Article 4 (1) of the E-Commerce Directive, Member States shall ensure that the taking up and pursuit of the activity of an information-society service provider is not made subject to prior authorisation or any requirement having equivalent effect.

The ISSA sets forth the principle, stemming from the above-mentioned directive, that the provision in Estonia of services belonging to the co-ordinated field through a place of business located in a member state of the EU or member state of the EEA is not subject to restriction, except in the case of protection of morality, public order, national security, public health, and consumer rights and to the extent justified for this (Subsection 3 (2)). Any restriction must be established with regard to a specific information-society service, and it must be proportional to its objective; before establishing a restriction, a competent Estonian body shall have asked the state of the location of the place of business to establish a restriction, whereupon the latter did not establish that restriction or imposed an inadequate one; and a competent body shall have notified the European Commission and the relevant Member State of its intention to establish a restriction (Subsection 3 (3)).

In the Ker-Optika court case, the ECJ found that EU member states may not restrict the provision of e-health services solely for reason of a requirement that the patient and health-care provider be physically present simultaneously. The court ruled that, although the freedom of provision of information-society services originating in another Member State may be restricted on the basis of the E-Commerce Directive, it is not a proportional requirement either that the sale of contact lenses must be preceded by a consultation with an ophthalmologist or that contact lenses may be sold only in a physical location. Hence, consultation may be carried out online. ${ }^{*} 43$

On the basis of the conclusions reached in the Ker-Optika case, it is, in principle, possible to launch e-consultations without a corresponding activity licence, in keeping with Article 4 (1) of the E-Commerce Directive. A Member State may, for the reasons set out in Article 3 (4) of the E-Commerce Directive, prohibit e-consultations or impose a requirement of having physical premises for provision of services. In such a case, the measure must be appropriate for achieving the objective sought and may not go beyond what is necessary for reaching that objective.

The state is quite obviously able to justify the necessity of the activity-licence requirement by citing protection of national health. More questionable is the requirement of a physical location for information-society services. At first glance, the requirement appears untenable. A physical examination would be relevant in the case of specialised services that cannot be provided without performing of an examination, since the service would thereby not conform to the standard treatment. ${ }^{* 44}$ In the case of certain specialities, such as psychiatry, examination of the patient and physical contact between the doctor and patient are indeed not necessary, as the latter can be replaced by a videoconference. Yet, if justified by the patient's interests or important from the standpoint of health protection, for objectives such as ensuring treatment continuity via provision of health-care service that is not restricted solely to e-consultation, such that the doctor could, if necessary, call the patient in for a physical examination, the requirement of physical premises and face-toface treatment may be judged to be reasonable.

Considering that e-consultation can be viewed as an information-society service and that provision of such a service may be restricted only on the grounds provided for in the ISSA, the author of this article maintains that the situation requires more thorough analysis, which is beyond the scope of the article, ${ }^{*} 45$ so that it can be determined whether the requirement of having physical facilities for e-consultations is justified on the basis of the purpose of protecting national health or on other grounds specified in the E-Commerce Directive and, furthermore, whether that requirement is appropriate for reaching the objective. Elsewhere

\footnotetext{
ISSA, Subsection 3 (1).

ECJ, 2 December 2010, Case C-108/09, Ker-Optika Bt. v. ÀNTSZ. - ECR 2010 I-12213.

44 E.g., the Estonian Society of Traumatologists and Orthopaedists maintains in statements to the EHIF that development of e-services in surgical specialities is complicated. There are almost no patients whose need for operative treatment could be decided upon without the patient being seen in person. The letter addressing this point is in the possession of the author.

45 The author plans to analyse the topic in her doctoral dissertation.
} 
in the world, e-consultations between a health-care professional and a patient without a physical appointment do take place. ${ }^{*} 46$

\section{Conclusions}

To an increasing extent, medical consultation is being provided over the Internet. Yet not all consultation in the field of medicine can be construed as a health-care service. Health-care services encompass only those e-consultations that are aimed at preventing, diagnosing, and treating diseases with the goal of reducing a person's complaints, preventing the deterioration of that person's state of health or the development of diseases, and restoring health. A health-care service as defined in the HSOA can be provided only by a health-care professional. In the interests of legal certainty and clarity, the current conflict in the definition of provision of a health-care service should be eliminated - to deal with the fact that, in essence, health-care services are also provided by specialists who are not health-care professionals - and clear criteria should be set that address how to distinguish an e-consultation from general consultation over the Internet. Intermediation of a health-care service over the Internet cannot be considered e-consultation. E-consultation over the Internet is an activity that is subject to an authorisation obligation, and the HSOA specifies the legal formats in which provision of e-consultation is permissible. A prerequisite for applying for an activity licence for e-consultation is the existence of physical facilities for provision of the service, but this becomes an obstacle to those who wish to provide only e-consultations. Because e-consultation is also an information-society service, the requirement of having physical facilities must be justified by the goal of protecting morals, public order, national security, national health, and consumers; must be appropriate for achieving the objective pursued; and may not go beyond what is necessary for that objective. To sum up, one can state that e-consultations are possible and legal within the lines of the existing legal framework but that there are still restrictions on initiating provision of a service and that a lack of clarity remains with regard to the definition of health-care service.

46 The Finnish company MeeDoc Oy offers, via its Web site fi.meedoc.com, consultations with physicians and prescription of medicinal products via video call or chat service for patients in Finland, Sweden, Norway, Ireland, England, and Spain. Also, through its Web site medgate.com, Swiss telemedicine centre Medgate offers around-the-clock e-consultation, issuing prescriptions and certificates of incapacity for work if necessary. 